$\xi=$ 离

\title{
Experiences of registered nurses on communication with Deaf patients at Katutura state hospital, Namibia
}

\author{
Simasiku Lunza *, Nghitanwa Emma \\ University of Namibia, Faulty of Health Sciences, School of Nursing \\ *Corresponding author E-mail: enghitanwa@unam.na
}

\begin{abstract}
The purpose of this study was to explore the experience of registered nurses on communication with Deaf patients. Data was collected using an interview guide. Random sampling technique was employed. Data was transcribed and keywords were identified representing the major categories. Data was analysed using a systematic process in order to deduce themes and sub-themes. During data analysis similar ideas or keywords were coded and similar topics were grouped together into categories. The study concluded that registered nurses lack sign language skills hence their communication with Deaf patients is also challenged. It is recommended that registered nurses needs to be provided with the training in sign language at educational institutions and provision of in-service training on sign language should made available for all health care workers. The study also recommends that Deaf people should be trained in sign languages for effective communication when seeking health care.
\end{abstract}

Keywords: Communication; Hearing; Deaf; Patient; Perception; Registered Nurse

\section{Introduction}

According to the World Health Organization (WHO), in 2011 about 360 million were living with hearing impairment globally (Olusanya et al., 2014), of which about $80 \%$ lives in the developing countries (Óladóttir, 2014). Hearing impairment is defined as a permanent unaided hearing loss averaged over frequencies of 0.5 , 1,2 and 4 kilohertz $(\mathrm{kHz})$ of more than 40 decibels $(\mathrm{dB})$ in a better ear in adults and $30 \mathrm{~dB}$ in children ( WHO 2013.) Hearing impairment affect interpersonal communication, psychosocial well-being and quality of life (Kotby et al., 2008). In this article's context and according to the Deaf cultural beliefs, Deaf with a capital D refers to people who lost their hearing before they acquired a language and for whom sign language is the first language of choice (Gilchrist, 2000).

It's an important distinction, because Deaf people tend to communicate in sign language as their first language. Furthermore, Deaf people are communicating with hand movements, facial expressions of the muscles, position of the head and upper part of the trunk (Hòrnňáková and Hudáková, 2013). Deaf people are entitled to use health facilities similar to the general population without being discriminated. (Watson, 2011). In addition, nurses should be able to communicate effectively with Deaf patients for effective quality nursing care (Dickson et al., 2014). However, only few health care professionals has been trained on communication with Deaf patients (Dickson et al. 2014). As a result, most Deaf patients depend on interpreters when seeking health care, as they experiences communication barriers with health care providers (Newman, 2008). The using of interpreter can affect ethical standards and patient's confidentiality and privacy (Agrawal et al ., 2008). However, failure to use the interpreter can end up in miscommunication and misdiagnoses if the health care provider is not convenient with sign language. Furthermore, medication errors, misdiagnoses and treatment non- adherence could also increase with communication challenges (Dickson et al., 2014).

In the United States of America (USA) the American with Disability Act (ADA) makes provision for effective communication in the hospitals between Deaf patients, family members or visitors such as exchanging written notes, using qualified interpreters by the hospitals (USA Department of Justice ,1990).

In Namibia, according to the 2011 Namibia Housing Census, the total number of deaf people was estimated at 6.257 (3.196 female and 3.061 male) and more Deaf people are living in urban areas (Namibia Statistics Agency, 2013). The National Disability Act (2004) of Namibia highlights the right of the people with disability which promote and strengthen the usage of Namibian Sign Language in for communication amongst Deaf people and between Deaf and hearing people. Furthermore, the Act, (Disability Act 2004 ) encourages the government to ensure that interpreter services with qualified sign language interpreters are developed to facilitate appropriate communication between deaf and hearing people ( Republic of Namibia, 2004 ) . However, there was no study conducted among registered nurses to assess their experience regarding communication with the Deaf patients in Namibia.

\section{Purpose of the study}

This study purpose was to explore the experience of registered nurses on communication with Deaf patients during health care provision.

\section{Objective of the study}

The objectives of the study are to: 
- Investigate experiences faced by registered nurses in communicating with Deaf patients

- To explore the factors that may contribute to communication challenges between Deaf patients and registered nurses.

- To explore with nurses any interventions that may be used to tackle challenges facing registered nurses during provision of health care to the Deaf patients.

\section{Methodology}

This study was conducted using a qualitative, cross - sectional, explorative and descriptive study design using face to face interview to investigate the experience of registered nurses on communication with Deaf patients. Data was collected among registered nurses in Katutura State Hospital, Namibia. The study population were Registered nurses in Katutura hospital at the outpatient department. Katutura hospital is an intermediate referral hospital, situated in Windhoek, a capital city of Namibia.

The sample comprised of ten registered nurses of which two males and eight females were selected on purposive sampling .The inclusion criteria was registered nurses working in the outpatient department rendered nursing care to the Deaf patient. The pilot study was conducted to pre-test the methodology and the feasibility of the study among three registered nurses at the outpatient department. Feedback from the pilot testing were incorporated before the main study. Participants for pilot testing were excluded from the main study.

Data was collected though in depth interview using interview guide. The interview guide contains three main questions. Ques tion one assessed the experience of registered nurses in communicating with Deaf patients, question two contains possible contributing factors for communication challenges faced by nurses when rendering health care to Deaf patients, while question three was about possible interventions which may improve the communication challenges between Deaf patients and registered nurses. Data was collected in the private office for each participant to ensure privacy. The aim of the study was explained to the participants and consent was signed for the permission to participate in the study before data collection commenced. Interviews were audio recorded and field notes were taken. Data saturation was reached after interviewed ten registered nurses. Data was collected for a period of two weeks. No incentives were given to the participants. Data was analysed using thematic analysis. Audio recorded data were transcribed verbatim. Data was compared to determine variations and similarities and themes and sub -themes were identified.

\section{Result}

Three themes and seven sub-themes are discussed in this chapter and were identified using a TESCH's method ((Tesch, 2013). The themes and sub-themes are presented in the table below.

\begin{tabular}{|c|c|}
\hline Themes & Sub-themes \\
\hline $\begin{array}{l}\text { Participants described their } \\
\text { communication with Deaf } \\
\text { patients }\end{array}$ & $\begin{array}{l}\text { - Communication challenges expe- } \\
\text { rienced between participants and } \\
\text { Deaf patients } \\
\text { Poor communication due to lack } \\
\text { of sign language training among } \\
\text { participants }\end{array}$ \\
\hline $\begin{array}{l}\text { Participants described factors } \\
\text { contributing to improper } \\
\text { communication to Deaf pa- } \\
\text { tients }\end{array}$ & $\begin{array}{l}\text { Shortage of staff leads to time } \\
\text { constraint } \\
\text { Lack of qualified sign language } \\
\text { interpreters on the health facilities } \\
\text { Lack of patient's privacy when } \\
\text { utilizing patient's family mem- } \\
\text { bers as interpreters }\end{array}$ \\
\hline $\begin{array}{l}\text { Interventions to improve } \\
\text { communication between Deaf } \\
\text { patients and registered nurses }\end{array}$ & $\begin{array}{l}\text { Training of registered nurses on } \\
\text { sign language } \\
\text { Employing qualified sign lan- } \\
\text { guage interpreters on all health } \\
\text { facilities }\end{array}$ \\
\hline
\end{tabular}

\subsection{Participants described their communication with deaf patients.}

The current study results revealed that there is poor communication among the participants and Deaf patients. The following subthemes were developed in this regard:

\subsubsection{Sub-theme: communication challenges between partici- pants and deaf patients}

Participants expressed difficulties in communication with Deaf patients and mostly worried of miscommunication which may lead to misdiagnosis, delayed treatment or poor health care provision. Participants indicated the strategies they use at times by writing on a piece of paper especially if the Deaf patient is capable of reading and writing. Most of the participants indicated that they sometimes try to communicate by using physical expressions and pointing with their hands to try to find out where the problem is which they stated how challenged it is due to the lack of mutual understanding between the nurse and the Deaf patients. Furthermore, it was indicated by the participants that, Deaf people are not given health education due to the communication challenges. Some participants were quoted as follow:

"Mhh... (pause ) ... we are challenged when communicating with Deaf people especially with history taking ... mhh...let me say the patient indicated by touching his/her head and you want to ask a follow up questions such as pain intensity or duration, you just don't know what to do".

Other participants were quoted:

"The communication with Deaf patients is difficult because we don't understand each other and you do not get the information that you want to get."

"To communicate with Deaf people is very challenging because you can't even give them health education".

\subsubsection{Subtheme: poor communication due to lack of sign lan- guage training among participants}

Participants reported that due to lack of sign language skills they are not able to communicate with Deaf patients. Participants reported that they have experienced difficulties using nonverbal communication with Deaf patients through sign language in order to understand each other in the exchange of information during health care service delivery. Some of the participants expressed themselves during the interview how difficult it was to communicate with the Deaf patients as they did not receive any sign language training during their basic nursing training or through inservice education. Participants further stated that most of the times patients can only point parts of her body by touching and nurses write in the patient's health passport according to their own understanding. Here are the quotes from the participants:

"It is difficult because I did not attend any workshop or any guidance how to communicate with Deaf patients."

"Sometimes it is difficult to check whether the patient understand and sometimes Deaf patients nod or smile in response to what has been said even though they may not fully understand and may not let nurses know that they did not understand what has been said ". The other participants responded in a similar and supporting idea: "Very terrible, because I have never attended sign language training, and I don't have any Deaf family member to exercise my sign language communication skill outside workplace, I would appreciate if the employer could provide us with in-service training in sign language".

Other participants stated as follow:

"Most of the times for those ones that can read you give them a pen and paper. You write your question and they write their answer or again you use facial expression and nonverbal communication by pointing in the body parts, which is not enough in history taking." 


\subsection{Participants described factors contributing to im- proper communication between deaf patients and regis- tered nurses}

Participants indicated different factors that hinder the proper communication between the registered nurses and Deaf patients as shortage of staff, lack of qualified sign language interpreters and lack of privacy on utilizing patient's family members as sign language interpreters as described here after.

\subsubsection{Shortage of staff leads to time constraint}

Most participants indicated that due to the staff shortage they find it difficult and time consuming to go around the hospital looking for other nurses with sign language skill to assist with the sign language interpretation. Participants also indicated that sometimes they do not give enough attention to Deaf patients due to the time constraints and they go ahead what they think is correct although they feels that the communication is not adequate. Some participants were quoted as follow:

"It is very difficult when it comes to history taking because you still don't get what they are trying to say unless they maybe use pen and paper which is also time consuming and you end up spending the whole day taking history with pen and paper while you are expected to attend to other patients".

One participant was quoted as follow:

"With this staff shortage, if you waste the time attending to one patient to try sign language which you don't know, you will end up with many patients going back home untreated. Is better to write and treat the Deaf patients based on the way you understand their expression".

\subsubsection{Lack of qualified sign language interpreters on the pub- lic health facilities}

Participants indicated that the public health sectors does not recruit sign language interpreters which is negatively affecting the communication between the health care professionals and the Deaf patients. Some participants reported that due to the lack of sign language interpreters they usually communicate with Deaf patients by writing a question on the piece of paper and give them a pen to answer by writing back, but this is possible only with those patients who are able to read and write. The following statements are evidence of this:

It's very difficult sometimes you are forced to let the person write on a piece of paper but it's not all of them who can write. You can try by all means to use the sign language but sometimes you fail to understand each other's.

"We don't have sign language interpreters here, and we sometimes depend on few colleagues who know some basic sign language".

\subsubsection{Lack of patient's privacy by utilizing patient's family members as interpreter}

Participants expressed that privacy is not being practiced when it comes to treating Deaf patients because sometimes family members are being asked to translate for them. Participants also stated that when using family member as a sign language interpreter they tend to exclude the patients in the care by only paying attention what the interpreter says which violates patients' right and dignity.

\subsection{Interventions to improve communication to deaf patients}

In this current study participants indicated strategies that could improve the communication between Deaf patients and registered nurses in order to provide quality nursing care. Most of the participants focused on the training of registered nurses on sign language in order to improve communication and the recruitment of qualified sign language interpreter to interpret during the communication between nurses and Deaf patients.

\subsubsection{Training of registered nurses on sign language}

Most participants indicated that sign language training is the only way that can improve communication with Deaf patients during the provision of healthcare. Participants feel that through sign language communication the right information from the patients will be obtained and proper quality nursing care could be provided. The following were expressed by participants during the interview.

"Is very difficult because we are not taught the sign language during our nursing training, so , the government should ensure that all registered nurses are trained on sign language".

"I learnt a lot through being challenged during rendering care to the Deaf patients, I think I need to learn sign language, because it's not easy communicating with Deaf patients and it's difficult to treat the patient you cannot communicate with because when Deaf patients show you signs you do not understand".

"The deaf people are neglected and lonely as cannot communicate to other patients either. Sign language education should be introduced to all health care professionals to make them welcome and make it easy to able communicate with us".

"I feel that training institutions should introduce sign language in the nursing curriculum for the importance of communication with Deaf patients “.

5.3.2. Employing qualified sign language interpreters on the public health facilities

All participants reported the lack of sign language interpreter in their work. Participants feels that the Ministry of Health and Social Services should employ qualified sign language interpreters to improve the communication between Deaf patients and registered nurses. One participant was quoted as follow:

"I have never seen any sign language interpreter in the public health facilities. I wonder whether the government is unable to recruit them like the Namibian Broadcasting Corporation (NBC) which uses sign language interpreters to translate the news in to the sign language".

\section{Discussion}

The current study aim was to explore and describe the experience of registered nurses on communication with Deaf patients in Katutura State Hospital, Namibia. In depth individual face to face interviews were conducted among registered nurses to obtain the data regarding the research question as discussed below. Emanated themes are discussed as follow.

\subsection{Theme 1: nurses describe their communication with deaf patients}

Under this theme two sub themes emerged namely: communication challenges and poor communication due to lack of sign language training among registered nurses. Participants indicated the communication challenges they are faced with when rendering health care to Deaf patients due to communication barriers. Effective communication facilitate patient and nurses relationship (Machado, 2013). Similar study by Hajbaghery and Shahsavarlol (2014) among nursing and midwifery students in Iran supported this current study findings were by very high communication challenges with Deaf patients were experienced by the majority (90\%) of the participants .

In addition, participants indicated that they had never attended any sign language training which make it difficult to communicate with Deaf patients. This finding is supported by Machado,s et al., ( 2013 ) study on how nurses interacts with Deaf patients in Rio de Janeiro, which found out that the majority of nurses indicate the lack of understanding of sign language due to lack of sign language training. Machado et al (2013) stated that nursing staff challenges in communicating with Deaf patients is a common aspect 
and recommended that communication challenges could be prevented by including sign language education in the nurses training

\subsection{Theme 2: participants described factors contrib- uting to improper communication to deaf patients}

Effective communication between the health professional and the patient is for utmost importance. Several factors were mentioned as contributing to poor communication with Deaf patients, such as time constraint, lack of sign language interpreters and lack of patient's privacy when family member is used as sign language interpreters.

In addition, time constraints due to the shortage of staff among registered nurses is reported by many participants as contributed to poor communication with Deaf patients in this current study. Shortage of nursing staff is a concern in Namibian public health which affects quality nursing care (Awases et al., 2013). Similar findings were recorded in the study by Hemsley et al., (2011) which explore the nurse's experiences on lack of time when caring patients with communication needs and patients communicate at slow rate. The findings indicated that participants indicated time as a challenge and nurses stated that they prefer to communicate with family members or recruited sign language interpreters instead of the patients. However, one third of participants indicated that allocation of time depend on the patient load, so if the load is light nurses allocated extra time for communication. Furthermore (McAleer, 2006) indicated that nurses compromises health care due to the shortage of staff and time constraint

Lack of sign language interpreters in the health facilities was also stated by participants as a barrier to communication between Deaf patients and registered nurses. A sign language interpreter is qualified if he or she can interpret competently, accurately, and impartially (United States Department of Justice, 2003). In the health care setting, the interpreter must be trained and familiar with any specialized vocabulary used and must be able to interpret medical terms and concepts.

Study by Óladóttir (2014) on explaining development and deafness in Namibia supported the current study findings as it revealed that lack of sign language interpreters is a barrier. Nevertheless (McAleer 2006) stated that nurses with sign language skills but not trained as sign language interpreters should not be used as interpreters as they are not trained in medical terms which may compromise communication. Meanwhile, the World Health Organization (WHO) (2013) stated the importance of training Deaf people and their families in sign language in order to facilitate effective communication between Deaf people and hearing people. The current study findings shows that participants felt that privacy of the Deaf patient is negatively affected when the registered nurses are using family members as sign language interpreters. The findings of the current study is similar with Steinberg et al (2006) when conducted a study among deaf population which shows that participants indicated that using family member as a sign language interpreter compromises Deaf patients privacy. Using qualified interpreters is important than using a person who is not trained in sign in sign language interpreting ( Mc Aleer, 2006).

\subsection{Theme 3: interventions to improve communication to deaf patients}

The current study findings shows that certain interventions would improve communication between registered nurses and Deaf patients such as training of registered nurses in sign language and recruitment of qualified sign language interpreters in all public health facilities. This study findings is supporting Dickson and Magowan (2014) on the study about meeting Deaf patient's communication needs which indicated that only few Deaf people are trained in sign language and lower level of education leads to lack of knowledge on disease symptoms, causes, prevention and treatment. The role of sign language interpreting services is to build communication bridges between hearing and Deaf for the benefit of both groups (Óladóttir, 2014). In the United Kingdom (UK) the
Department of Health (2005) highlights the importance of training all frontline healthcare workers in sign language to improve communication which is differ from the Namibian context.

Another finding from the current study is the employment of sign language interpreters in all public health facilities to improve communication as reported by the participants. The current study finding is supporting the study conducted by Steinberg et al (2006) to explore the experience of Deaf patients in the USA when seeking health care. The study revealed that participants stated that they experienced communication difficulties which improves when there are certified medical sign language interpreters or health professionals with sign language skills. The finding could be understood that qualified sign language interprets play an important roles in assisting in communication between health care professionals and Deaf patients.

The current study finding is supported by Machado et al., (2013) on the study in Rio de Janeiro regarding assessing how the nursing staff interact with Deaf patients, which revealed that only $3.85 \%$ participants used a sign language interpreter while most of the nurses $(46.15 \%)$ had used mime followed by $30.77 \%$ whom used lip reading. This finding is indicating that only very few sign language interpreters were available to assist with communication with the Deaf patients.

\section{Ethical consideration}

Approval was obtained from the Ministry of Health and Social Services, Research Ethical committee before conducting the study. Participants were interviewed in an office where there are no other people to ensure privacy and confidentiality. The researchers explained the purpose of the study to the participants and after verbal agreement to participate in the study participants were asked to read and sign the informed consent. Privacy and anonymity of the participants were maintained and no participants name were mentioned. Participants were informed of the right to refuse to answer certain questions or to withdraw from the study any time if they wish. Confidentiality was ensured and maintained throughout the study and after the study. The participants were informed that their responses will also be recorded and they have an option to listen to the audio recorder on completion of the study for data validation.

\section{Conclusions}

The current study shows that there are communication challenges faced by registered nurses and Deaf patients. Professional communication is an integral part of health care professional's work and also affects the quality of life for Deaf patients. It is therefore necessary to improve the communication between Deaf patients and registered nurses for mutual understanding in order to provide quality nursing care. The communication could be improved if registered nurses and Deaf patients are trained on sign language so that they could understand each other. Registered nurses should also allocate enough time to communicate with the Deaf patients for proper diagnoses and treatment regardless of the patient loads. Furthermore employing sign language interpreters in all public health facilities may improve communication between Deaf patients and registered nurses. The researchers recommended that further studies should be conducted in other health care facilities to assess the experience of Deaf patients on communication with health care professionals.

\section{References}

[1] Agrawal, Y, Platz, E.A and Niparko, J.K (2008). Prevalenceof hearing loss and differences by demographic characteristics among US adults. Archives of internal medicine. 168(14), 1522and 1530.

[2] Awases, MH, Bezuidenhout, MC \& Roos, JH. 2013. Factors affecting the performance of professional nurses in Namibia. Journal of the Democratic Nursing Organisation of South Africa. 36 (1): 1-8. https://doi.org/10.4102/curationis.v36i1.108. 
[3] Dickson, M and Magowan, R.2014. Meeting Deaf patient's communication needs. Nursing Times.110 (49) 1-15.

[4] Gilchrist, KL. 2000. Through the Looking Glass: The lived Experiences of Deaf People Communicating with Nurses. Denver, CO: University of Colorado.

[5] Kotby, MN, Tawfik, S, Aziz, A and Taha, H.2008. Public health impact of hearing impairment and disability. Folia Phoniatr Logop. 60: 58-63. https://doi.org/10.1159/000114646.

[6] Hajbaghery, MA \& Shahsavarloo, ZR.2014. Assessing the Nursing and Midwifery Students Competencies in Communication with $\mathrm{Pa}$ tients with Severe Communication Problems. Nurs Midwifery Student Journal. 3 (2): 1-7.

[7] Hemsley, B, Balandin, S and Worrall, L.2011. Nursing the patient with complex communication needs: time as a barrier and a facilitator to successful communication in hospital. Journal of Advanced Nursing. 68 (1):116-126. https://doi.org/10.1111/j.13652648.2011.05722.x.

[8] Hòrnňáková, A, Hudáková, K. (2013). Effective communication with deaf patients. JAHR .4 (7):157-166.

[9] Machado, W.C.A, Machado, DA, de Figueiredo, NMA, Tonini, T, de Miranda, R \& de Oliveira, GMB. 2013. Sign Language: How the Nursing staff interacts to take care of deaf patients? Revista de Pesquisa: Cuidado e Fundamental. 3 (5): 283-292. https://doi.org/10.9789/2175-5361.2013v5n3p283.

[10] McAleer, M .2006. Communicating effectively with deaf patients.
Nursing
standard.
20
(19).
$51-54$ https://doi.org/10.7748/ns.20.19.51.s57.

[11] Namibia Statistic Agency, 2013. Namibia Population and Housing Census 2011. Republic of Namibia. Windhoek.

[12] Newman, M.A. (2008). Transforming presence: The difference that nursing makes. Philadelphia. Olusanya, BO, Neumann, KJ \& Saunders, J.2014. The global burden of disabling hearing impairment: a call to action. Bull World Health Organ. 92:367-373. https://doi.org/10.2471/BLT.13.128728.

[13] Òladòttir, IÁ.2014. Meaning of Deaf Empowerment Exploring Development and Deafness in Namibia. MA thesis. University of Iceland.

[14] Republic of Namibia. 2004. National Disability Council Act 2004 (Act No.26 of 2004). Government printer. Windhoek. Steinberg, AG, Barnett, S, Meador, HE, Wiggins, EA and Zazove, P. 2006. Health care system accessibility. Experience and perceptions of deaf people. Journal of General Internal Medicine. 21 (3). 260-266.

[15] Tesch, R. 2013. Qualitative Research: Analysis Types \& Software Bristol. PA: Falmer Press.

[16] United States Department of Justice Civil Rights Division. 2003. ADA Business BRIEF: Communicating with People Who Are Deaf or Hard of Hearing in Hospital Settings. From: https://www.ada.gov/hospcombr.htm. (Accessed on 20/07/2016).

[17] United States Department of Justice Civil Rights Division. 1990 Information and Technical Assistance on the Americans with Disabilities Act. United States of America. Washington DC.

[18] Watson, J. 2011. Caring knowledge and informed moral passion. Philadelphia: Lippncott.

[19] World Health Organization (2013).Deafness and hearing loss From: htttp://www.who.int/mediacentre/factsheets/fs300/en/ (accessed on 17 July 2016). 